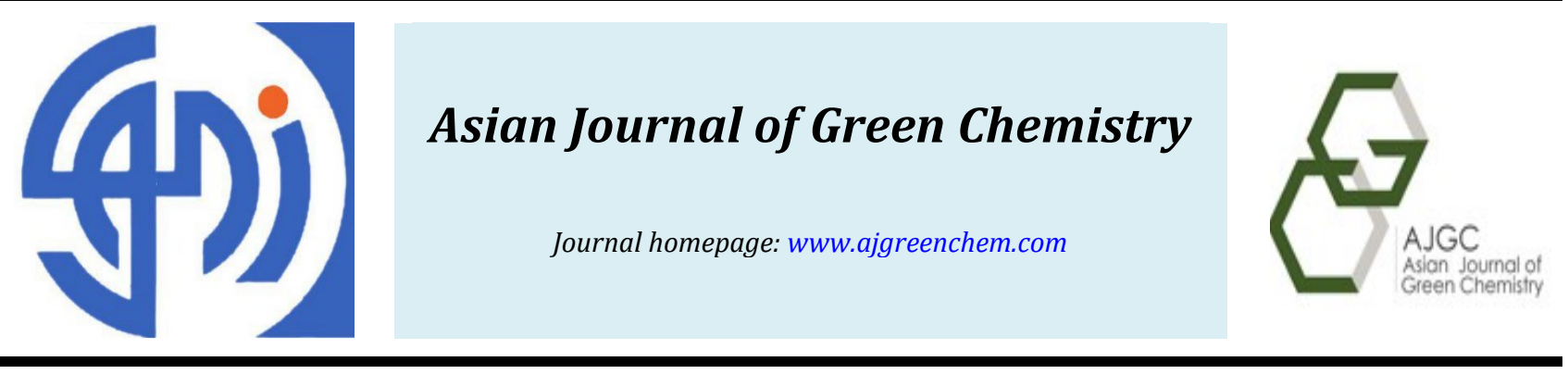

Original Research Article

\title{
Efficient and green synthesis of trisubstituted imidazoles by magnetically nanocatalyst and microwave assisted
}

\author{
Hamid Reza Mardani*, Mehdi Forouzani, Rasoul Emami \\ Department of Chemistry, Payame Noor University (PNU), PO BOX 19395-3697 Tehran, Iran
}

\author{
ARTICLE INFORMATION \\ Received: 25 October 2018 \\ Received in revised: 9 November 2018 \\ Accepted: 10 November 2018 \\ Available online: 4 February 2019 \\ DOI: $10.33945 / S A M I / A J G C / 2019.4 .9$

\section{KEYWORDS} \\ Imidazole \\ Benzil \\ Microwave irradiation \\ Green synthesis \\ Magnetic nanoparticles
}

\begin{abstract}
$\mathrm{Fe}_{3} \mathrm{O}_{4}$ magnetic nanoparticles $\left(\mathrm{Fe}_{3} \mathrm{O}_{4} \mathrm{MNPs}\right)$ were prepared and used as an eco-friendly, reusable, low-cost and efficient catalyst for the synthesis of 2,4,5-trisubstituted imidazoles via three-component reaction of aromatic aldehydes with benzil and ammonium acetate under low power microwave irradiation and solvent-free condition. This one-pot procedure was very simple with good to excellent yields. Easy separation of $\mathrm{Fe}_{3} \mathrm{O}_{4} \mathrm{MNPs}$ from the reaction mixture by an external magnet and the reusability of the catalyst were the considerable points of the reaction.

(C) 2019 by SPC (Sami Publishing Company), Asian Journal of Green Chemistry, Reproduction is permitted for noncommercial purposes.
\end{abstract}




\section{Graphical Abstract}

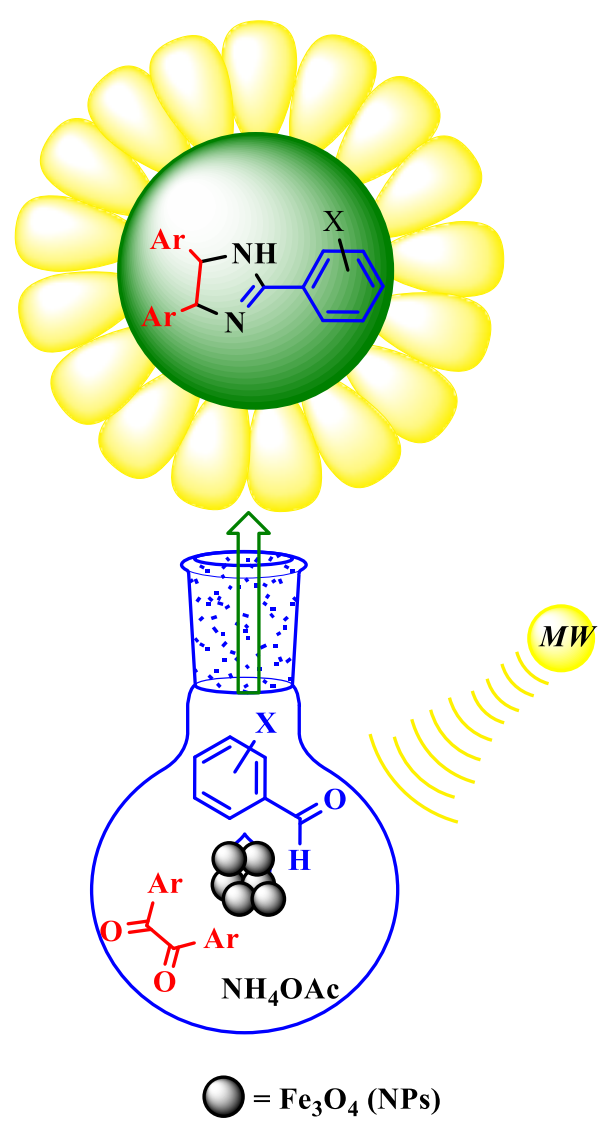

\section{Introduction}

Multi-substituted imidazoles are an important class of heterocyclic compounds with wide biological and pharmaceutical applications [1-3]. The substituted imidazoles are well known as inhibitors of P38 MAP kinase [4] and therapeutic agents [5]. Imidazoles chemistry, because of its use in ionic liquids [6] and in $N$-heterocyclic carbenes (NHCs) [7], gave a new dimension in the area of organometallics and "green chemistry". Other important features of these compounds are including, anti-inflammatory [8], anti-parasitic [9], antifungal [10], antidepressant [11], anti tubercular [12], anticancer [13] and antiviral activities [14], and anti leishmanial activity against the leishmania donovani [15].

There are many methods available in the literature which describe reliable synthesis of $2,4,5$ trisubstituted imidazoles via three-component condensation of aldehydes, benzyl and ammonium acetate at the presence of various catalytic species, such as acetic acid [16], silica sulfuric acid [17], $\mathrm{I}_{2}$ [18], $\left(\mathrm{Zr}(\mathrm{acac})_{4}\right)$ [19], $L$-proline [20], montmorillonite $\mathrm{K} 10$ [21], $\mathrm{Cu}\left(\mathrm{NO}_{3}\right)_{2}$-zeolite [22], ionic liquids [23-25], DABCO [26], urea-functionalized $\mathrm{Fe}_{3} \mathrm{O}_{4} / \mathrm{SiO}_{2}$ [27] and $\mathrm{Fe}_{3} \mathrm{O}_{4} @ \mathrm{SiO}_{2} \cdot \mathrm{HM}_{2} \mathrm{SO}_{3} \mathrm{H}$ under 
microwave irradiation at $450 \mathrm{~W}$ [28]. Despite the efficiency of the reported protocols, some of them suffer from some drawbacks such as long reaction time, harsh reaction conditions, corrosiveness, toxicity, cost, and reusability of catalyst.

In recent years, $\mathrm{Fe}_{3} \mathrm{O}_{4}$ MNPs have attracted a great attention in many different fields due to their intrinsic properties including, high surface area, low toxicity, super-paramagnetic behavior, and easy separation and recovery from the reaction medium by magnetic decantation [27-29]. In other words, the use of microwave for the synthesis of organic compounds under solvent-free condition has proved to be efficient, safe and environmentally benign technique, with shorter reaction time, high yields, and easier work-up [23, 30-32]. However, incorporation of the cyclo condensation pathway with MW irradiation and property of $\mathrm{Fe}_{3} \mathrm{O}_{4}$ MNPs causes imidazoles be achieved in higher yields and shorter time. Therefore, in this research study, we introduced the $\mathrm{Fe}_{3} \mathrm{O}_{4}$ MNPs as a green heterogeneous catalyst for the synthesis of 2,4,5-trisubstituted imidazoles via the three-component reaction of various aromatic aldehydes with ammonium acetate and benzil under solvent-free condition and low power microwave irradiation (Scheme 1).

\section{Experimental}

\section{Materials and Methods}

Chemical materials were purchased from Merck and aldrich chemical companies in high purity. Microwave irradiation was carried out by a kenwood microwave oven with power output of $1000 \mathrm{~W}$. The progress of the reactions and purity of the products were monitored by TLC (thin layer chromatography). The melting points were determined using the electro-thermal-IA9200 melting point apparatus. Fourier transform infrared spectroscopy (FT-IR) was recorded on a PERKIN-ELMER RXI spectrometer using $\mathrm{KBr}$ pressed powder discs. The NMR spectra were measured in pure deuteriated dimethyl sulfoxide (DMSO- $\mathrm{d}_{6}$ ) as solvent on a Bruker avance $400 \mathrm{MHz}$ instrument $\left({ }^{1} \mathrm{H}\right.$ NMR $400 \mathrm{MHz}$ ) with tetramethylsilane (TMS) as the internal reference. The XRD data of the synthesized nanoparticle was obtained with a Bruker x-ray diffractometer (Advanced-D8) using CuK $\alpha$ radiation.

\section{Preparation of nano catalyst}

Synthesis of the $\mathrm{Fe}_{3} \mathrm{O}_{4}$ nanoparticles was carried out using a modified procedure [33]. A typical procedure, $5.2 \mathrm{~g}$ of $\mathrm{FeCl}_{3}$ and $2.0 \mathrm{~g}$ of $\mathrm{FeCl}_{2}$ were successively dissolved in $25 \mathrm{~mL}$ of double-distilled water containing $0.85 \mathrm{~mL}$ of $12.1 \mathrm{~N} \mathrm{HCl}$. The resulting solution was then added dropwise into $250 \mathrm{~mL}$ of $1.5 \mathrm{M} \mathrm{NaOH}$ solution under vigorous stirring. The last step generated an instant black precipitate. 
The precipitate was isolated in the magnetic field, and the supernatant was removed from the precipitate by decantation.

\section{General procedure for synthesis of 2,4,5-trisubstitutedimidazoles}

The aromatic aldehyde ( $1 \mathrm{mmol})$, benzils $(1 \mathrm{mmol}), \mathrm{NH}_{4} \mathrm{OAc}(5 \mathrm{mmol}, 0.385 \mathrm{~g})$ and catalyst $\left(\mathrm{Fe}_{3} \mathrm{O}_{4}\right.$, $0.05 \mathrm{gr}$ ) were mixed thoroughly in a glass vessel. The reaction mixture was irradiated in a domestic microwave oven at $200 \mathrm{~W}$ for appropriate time. After completion of the reaction, as monitored with TLC, the reaction mixture was cooled at room temperature. Then, $10 \mathrm{~mL}$ acetone was added into crude reaction mixture and the catalyst was separated using an external magnet. The products were obtained by the addition of $10 \mathrm{~mL}$ cold water to the acetone solution. Further purification by column chromatography and recrystallization gave the desired products. The products were characterized on the basis of their melting point, IR, ${ }^{1} \mathrm{H}$, and ${ }^{13} \mathrm{C}$ NMR spectra. It was found that the recovered catalyst could be used directly for five cycles without noticeable drop in the catalytic activity.

\section{2,4,5-Triphenyl-1H-imidazole}

$\operatorname{mp} 273-275^{\circ} \mathrm{C}$, IR (KBr) ( $\left.v_{\max } / \mathrm{cm}^{-1}\right): 3434,2993,2470,1638$, and 1216. ${ }^{1} \mathrm{H} \mathrm{NMR}$ (CDCl $/$ /DMSO-d6): $\delta 12.61$ (1H, brs), 7.42-8.12 (15H, m). ${ }^{13} \mathrm{C}$ NMR (CDCl 3 /DMSO-d6): $\delta 136.5,129.1,128.5,127.2,122.1$. Anal. Calcd. for $\mathrm{C}_{12} \mathrm{H}_{16} \mathrm{~N}_{2}$ : C, 85.11; H, 5.44; N, 9.45; Found: C, 85.02; H, 5.1; N, 9.12.

\section{2-(4-Methoxy-phenyl)-4,5-diphenyl-1H-imidazole}

$\operatorname{mp} 227-229^{\circ} \mathrm{C}$, IR (KBr) ( $\left.v_{\max } / \mathrm{cm}^{-1}\right): 3428,2893,2465,1636$, and $1216 .{ }^{1} \mathrm{H}$ NMR (CDCl $\left./ \mathrm{CDMSO}_{3} \mathrm{~d} 6\right)$ : $\delta 3.85(\mathrm{~s}, 3 \mathrm{H}), 12.52$ (1H, brs), 8.02-8.05 (2H, d), 7.25-7.59 (10H, m), 6.93-6.96 (2H, d), 3.85 (3H, s). ${ }^{13} \mathrm{C} \mathrm{NMR}_{\left(\mathrm{CDCl}_{3} / \mathrm{DMSO}-\mathrm{d} 6\right): \delta} \delta$ 159.1, 145.7, 132.8, 127.6, 126.5, 126.3, 122.7, 113.2, 54.6. Anal. Calcd. for $\mathrm{C}_{22} \mathrm{H}_{18} \mathrm{~N}_{2} \mathrm{O}$ : C, 80.96; H, 5.56; N, 8.58; Found: C, 80.68; H, 5.23; N, 8.42.

\section{2-(4-Chlorophenyl)-4,5-diphenyl-1H-imidazole}

$\operatorname{mp} 259-262{ }^{\circ} \mathrm{C}$, IR (KBr) $\left(v_{\max } / \mathrm{cm}^{-1}\right): 3447,1620$, and 1519. ${ }^{1} \mathrm{H} \mathrm{NMR}$ (CDCl $\left./ \mathrm{DMSO}_{3} \mathrm{~d} 6\right): \delta 12.71(\mathrm{br}$,

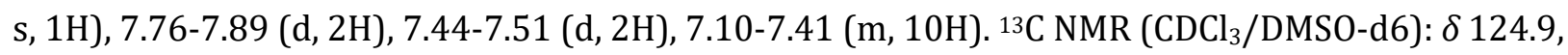

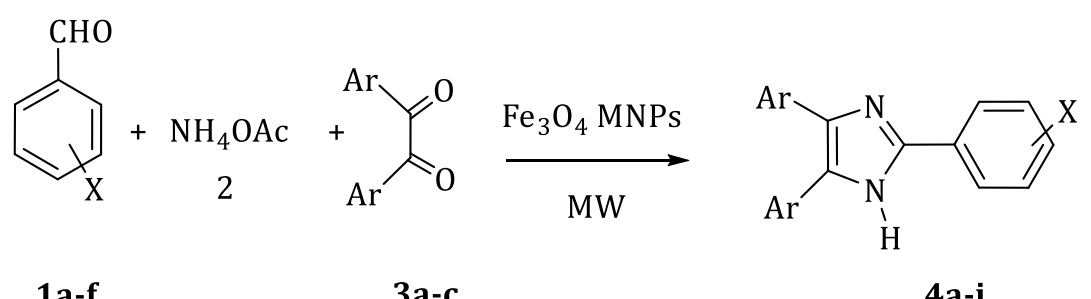

Scheme 1. Synthesis of trisubstitutedimidazoles using $\mathrm{Fe}_{3} \mathrm{O}_{4}$ MNPs under solvent-free and microwave irradiation conditions. 
126.3, 126.8, 128.1, 129.2, 129.9, 132.3, 143.9. Anal. Calcd. for $\mathrm{C}_{21} \mathrm{H}_{16} \mathrm{~N}_{2}$ : C, 76.25; 76.14; $\mathrm{H}, 4.53 ; 4.55$; N, 8.47; Found: C, 76.14; H, 4.55; N, 8.37.

\section{2-(4-Bromophenyl)-4,5-diphenyl-1H-imidazole}

$\operatorname{mp} 263-265^{\circ} \mathrm{C}$, IR (KBr) $\left(v_{\max } / \mathrm{cm}^{-1}\right): 3450,3070,1615$, and 1320. ${ }^{1} \mathrm{H}$ NMR (400 MHz, DMSO-d6): $\delta$ 12.68 (s, 1H), 8.15 (d, 2H), 7.50-7.13 (m, 12H). ${ }^{13} \mathrm{C}$ NMR (400 MHz, DMSO-d $)$ : 146.1, 130.5, 129.6, $129.1,128.4,127.2,127.0,126.6,125.5,125.1,123.0,116.2$. Anal. Calcd. for $\mathrm{C}_{21} \mathrm{H}_{15} \mathrm{BrN}_{2}$ : C, 67.21; $\mathrm{H}$, 4.03; N, 7.47; Found: C, 67.06; H, 3.71; N, 7.21.

\section{Results and Discussion}

$\mathrm{Fe}_{3} \mathrm{O}_{4}$ MNPs were synthesized according to the reported procedures in the literature [28]. The nano catalyst structure was characterized using FT-IR, SEM, and EDX [36]. For $\mathrm{Fe}_{3} \mathrm{O}_{4}$ nanoparticles, the broad peak observed at $584 \mathrm{~cm}^{-1}$ and $765 \mathrm{~cm}^{-1}$ should be attributed to the $\mathrm{Fe}-0$ stretching absorption, the peaks at 1637 and $3432 \mathrm{~cm}^{-1}$ are attributed to the $\mathrm{O}-\mathrm{H}$ of $\mathrm{H}_{2} \mathrm{O}$, similar to the literature. The XRD pattern of the prepared $\mathrm{Fe}_{3} \mathrm{O}_{4}$ nanomaterial was similar to the references information of library data. It has got 9 line, the position and relative intensities of the peaks are compatible with the cubic crystals. The average crystallite sizes of $\mathrm{Fe}_{3} \mathrm{O}_{4}$ was found to be $18.5 \mathrm{~nm}$. The EDX spectrum is demonstrated Fe and $\mathrm{O}$ elements in sample. The FESEM image showed a tiny spherical mushroom morphology for $\mathrm{Fe}_{3} \mathrm{O}_{4}$ (Figure 1).

In the next step, to assess the catalytic activity of $\mathrm{Fe}_{3} \mathrm{O}_{4}$ MNPs in the synthesis of 2,4,5trisubstituted imidazoles, the three component condensation of $P$-hydroxybenzaldehyde $\mathbf{1 b}(1$ mmol) with $\mathrm{NH}_{4} \mathrm{OAc} 2$ (5 mmol) and benzil 3a (1 mmol) was investigated as a model reaction under different conditions, and the results are summarized in Table 1. It was observed that, when the model reaction was carried out in the absence of any catalyst under solvent-free condition and microwave irradiation at $200 \mathrm{~W}$, no desired product was formed after 10 min (Table 1, entry 1).
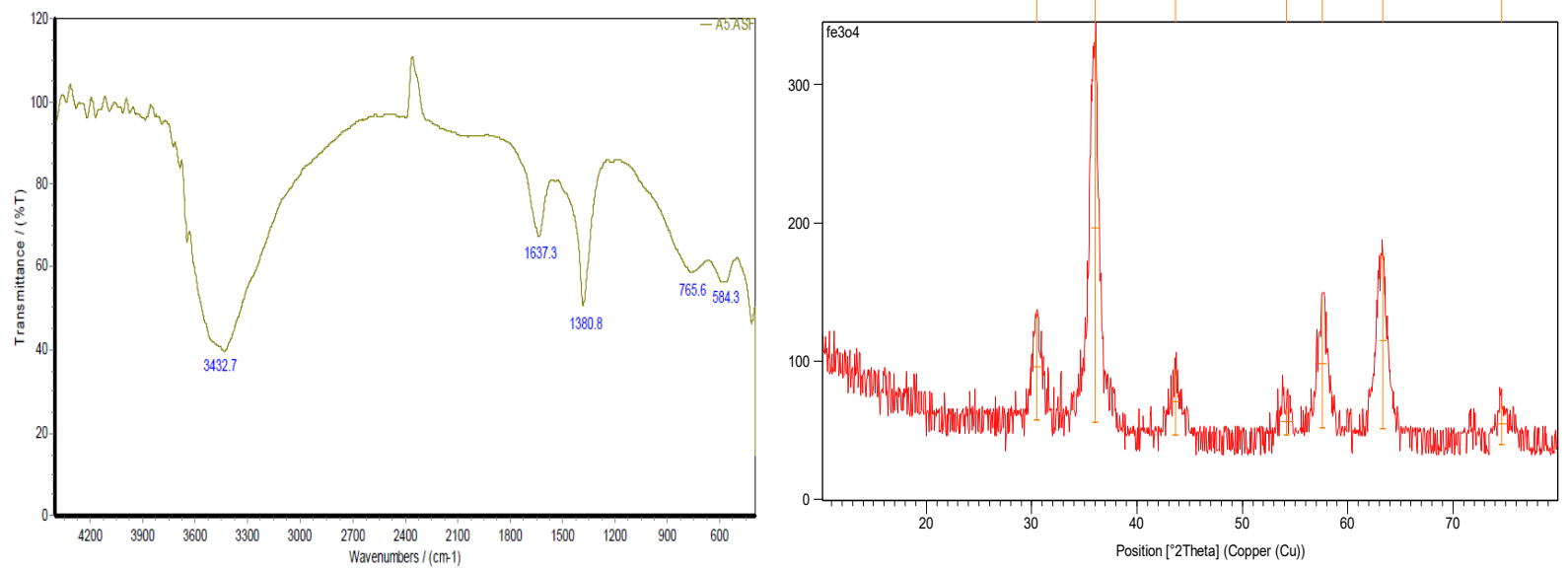

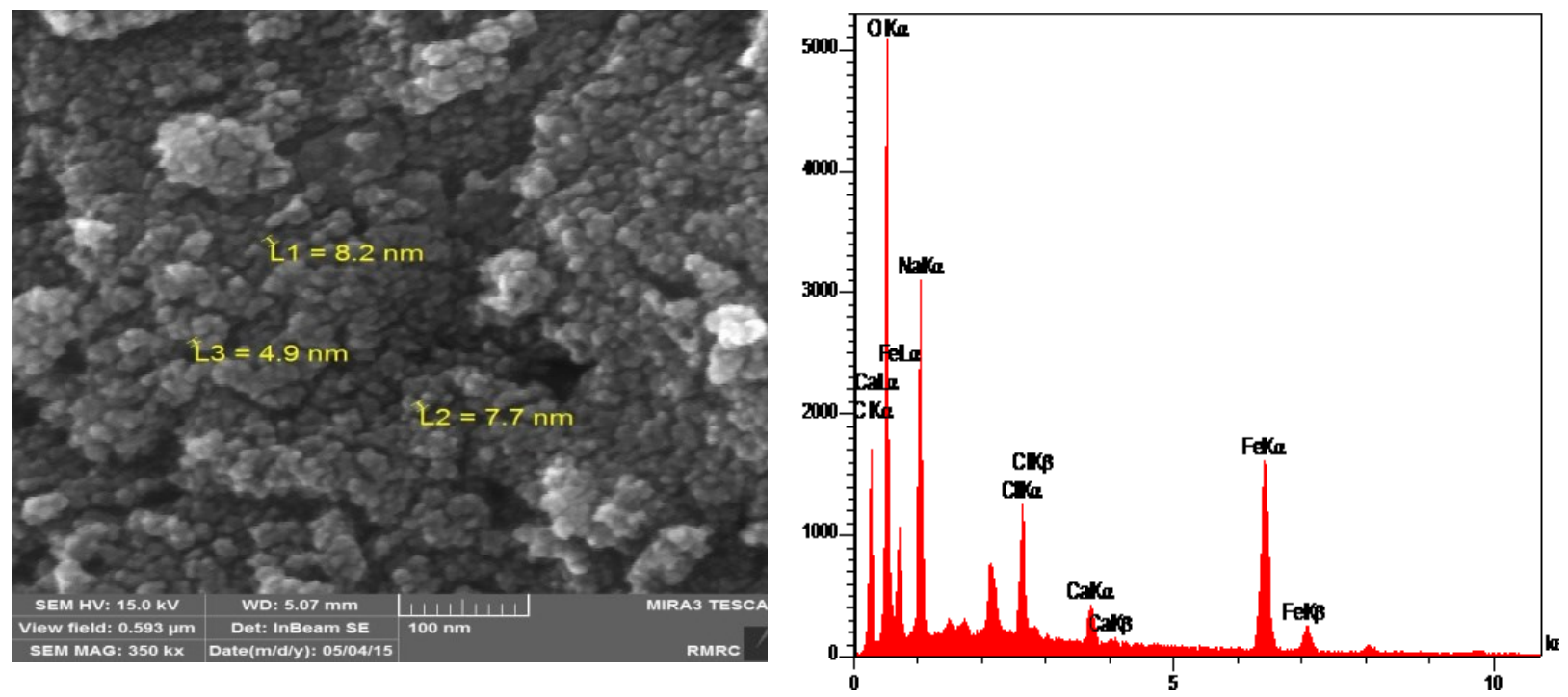

Figure 1. The FT-IR spectrum, XRD pattern, EDX and FESEM image of the $\mathrm{Fe}_{3} \mathrm{O}_{4}$

Table 1. Optimization of reaction conditions for the synthesis of 2-( $P$-hydroxyphenyl)-4,5-diphenyl imidazole 4b

\begin{tabular}{cccccc} 
Entry & Catalyst $(\mathrm{g})$ & Solvent & Power(w) & Time (min) & Yield (\%) \\
1 & - & - & 200 & 10 & - \\
2 & $\mathrm{SiO}_{2}(0.2)$ & - & 400 & 10 & trace \\
3 & $\mathrm{BaCl}_{2}(0.2)$ & - & 400 & 10 & 60 \\
4 & $\mathrm{Na}_{2} \mathrm{SO}_{4}(0.1)$ & - & 400 & 10 & 22 \\
5 & $\mathrm{Fe}_{3} \mathrm{O}_{4}(0.05)$ & - & 200 & 10 & 95 \\
6 & $\mathrm{Fe}_{3} \mathrm{O}_{4}(0.01)$ & - & 200 & 10 & 20 \\
7 & $\mathrm{Fe}_{3} \mathrm{O}_{4}(0.1)$ & - & 200 & 10 & 97 \\
8 & $\mathrm{Fe}_{3} \mathrm{O}_{4}(0.05)$ & - & 100 & 10 & 75 \\
9 & $\mathrm{Fe}_{3} \mathrm{O}_{4}(0.05)$ & - & 400 & 10 & 55 \\
10 & $\mathrm{Fe}_{3} \mathrm{O}_{4}(0.05)$ & $\mathrm{H}_{2} \mathrm{O}$ & 200 & 10 & 60 \\
11 & $\mathrm{Fe}_{3} \mathrm{O}_{4}(0.05)$ & $\mathrm{CH}_{3} \mathrm{CO}_{2} \mathrm{H}$ & 200 & 10 & 50 \\
12 & $\mathrm{Fe}_{3} \mathrm{O}_{4}(0.05)$ & $\mathrm{EtOH}_{13}$ & 200 & 10 & 70 \\
13 & $\mathrm{Fe}_{3} \mathrm{O}_{4}(0.05)$ & $\mathrm{THF}$ & 200 & 10 & 50 \\
14 & $\mathrm{Fe}_{3} \mathrm{O}_{4}(0.05)$ & $\mathrm{CH}_{2} \mathrm{Cl}$ & 200 & 10 & 50 \\
\hline
\end{tabular}

a Yields refer to isolated products 
Table 2. $\mathrm{Fe}_{3} \mathrm{O}_{4} \mathrm{MNPs}$ catalyzed synthesis of 2,4,5-trisubstituted imidazoles under solvent-free and microwave irradiation conditions ${ }^{\mathrm{a}}$

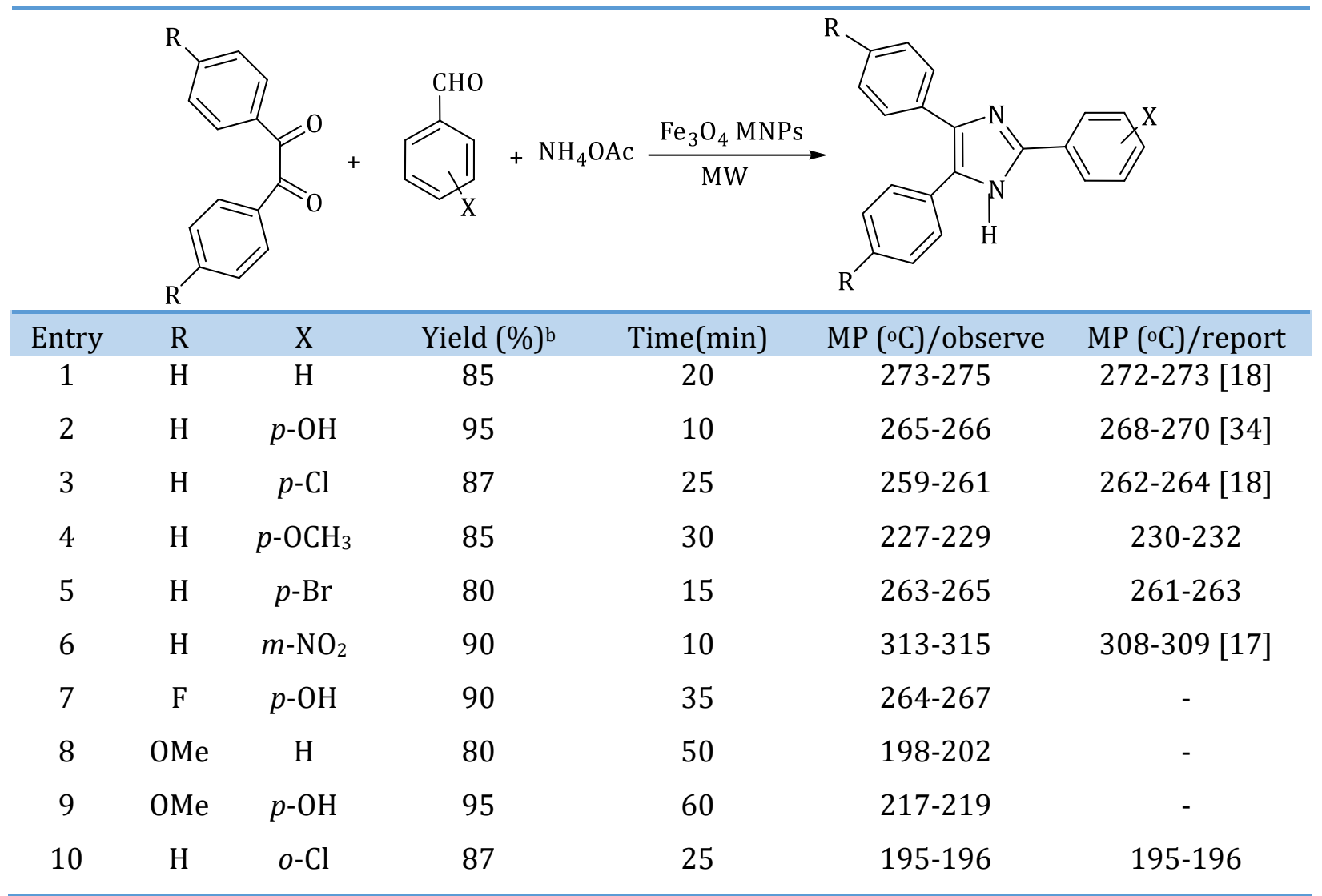

a The reaction condition: benzil $(1 \mathrm{mmol})$, aldehyde $(1 \mathrm{mmol})$, ammonium acetate salt $(5 \mathrm{mmol})$, solvent-free, microwave irradiated at $200 \mathrm{~W}$

${ }^{b}$ Yields of the isolated product

To explore the suitable reaction conditions, the above model reaction was performed at the presence of various catalysts such as nano $\mathrm{SiO}_{2}, \mathrm{BaCl}_{2}, \mathrm{Na}_{2} \mathrm{SO}_{4}$ and $\mathrm{Fe}_{3} \mathrm{O}_{4}$ MNPs under solvent-free and microwave irradiation conditions (Table 1, entries 2-5). The $\mathrm{Fe}_{3} \mathrm{O}_{4} \mathrm{MNPs}$ demonstrated superior catalytic activity among those examined (Table 1, entry 5). To investigate the effect of solvent, the condensation reaction of the model substrates was carried out in different solvents including $\mathrm{CH}_{2} \mathrm{Cl}_{2}$, $\mathrm{Et}_{2} \mathrm{O}$, THF, EtOH and $\mathrm{H}_{2} \mathrm{O}$ using $0.05 \mathrm{~g} \mathrm{Fe}_{3} \mathrm{O}_{4} \mathrm{MNPs}$ under the microwave irradiation conditions (Table 1, entries 10-15). Screening the solvent in this reaction revealed that the under solvent-free conditions, highest yield of the desired product is obtained as compared to the tested solvents (Table 1, entry 5).

We also evaluated the amount of catalyst required for this transformation. The amount of $\mathrm{Fe}_{3} \mathrm{O}_{4}$ MNPs, which afforded the best yields, was $0.05 \mathrm{~g}$. Increasing the amount of catalyst did not change the yield dramatically (Table 1, entry 7), whereas reduction of it significantly decreased the product 
yield (Table 1, entry 6). Then the reaction was studied at the presence of different molar ratios of $\mathrm{NH}_{4} \mathrm{OAc}$ (1-8 mmol) as an ammonia source, and the best result was obtained with $5 \mathrm{mmol}$ of $\mathrm{NH}_{4} \mathrm{OAc}$. Power of the microwave instrument was also optimized and the best operating power was found to be $200 \mathrm{~W}$.

To explore the generality and applicability of this catalyst a variety of aromatic aldehydes reacted with benzils and ammonium acetate under the optimal reaction conditions and the results are presented in Table 2. Aromatic aldehydes substituted with either electron-donating or electron-withdrawing groups underwent the reaction smoothly and in all cases the desired product was synthesized in high yield. As seen in Table 2, when 4,4'-dimethoxybenzil 3c was used instead of benzyl 3a, the reaction time was increased (Table 2, entries 8 and 9). The structure of products 4a-j was characterized on the basis of their ${ }^{1} \mathrm{H}$ and ${ }^{13} \mathrm{C}$ NMR, IR and mass spectroscopic data.

To evaluate the recyclability and stability of the catalyst, we designed a set of experiments by conducting successive condensation of model substrates using the recovered $\mathrm{Fe}_{3} \mathrm{O}_{4} \mathrm{MNPs}$ under by applying the optimized conditions. After the completion of the first reaction run, acetone was added to the reaction mixture and catalyst was easily removed by an external magnet and recovered simply by washing with $\mathrm{EtOH}$, and vacuum drying, and then reused for at least 4 times without observation noticeable drop in activity (Figure 2).

The proposed mechanism for the synthesis of trisubstituted imidazoles 4 can be described as shown in Scheme 2 [20-35]. $\mathrm{Fe}_{3} \mathrm{O}_{4}$ MNPs act as Lewis acid and play a significant role in increasing the electrophilic character of the aldehyde. Subsequently, the reaction of the activated aldehyde with two molecules of ammonia to afford diamine intermediate 5, which condenses with the carbonyl carbons of the benzyl at the presence of $\mathrm{Fe}_{3} \mathrm{O}_{4}$ MNPs followed by dehydration to form the imino intermediate 6, which rearranged to the desired trisubstituted imidazole 4.

\section{Conclusion}

In this study, we have confirmed a simple method for the synthesis of 2,4,5-trisubstituted imidazoles using $\mathrm{Fe}_{3} \mathrm{O}_{4}$ MNPs as an eco-friendly, reusable, low-cost, and efficient catalyst under low power microwave irradiation and solvent-free condition. Environmental acceptability, high yield of product, simple workup, easy removal, and recyclability of the catalyst are the most important features of this atom economical protocol. 
Figure 2. Reusability of

$\mathrm{Fe}_{3} \mathrm{O}_{4}$ NPs for the synthesis of $\mathbf{4 b}$, [Reaction conditions: benzil $(1 \mathrm{mmol}), P$ hydroxybenzaldehyde $(1$ mmol) and $\mathrm{NH}_{4} \mathrm{OAc}(1$ mmol), solvent-free, microwave irradiated at 200 $\mathrm{W}$; reaction time (10 $\mathrm{min})]$

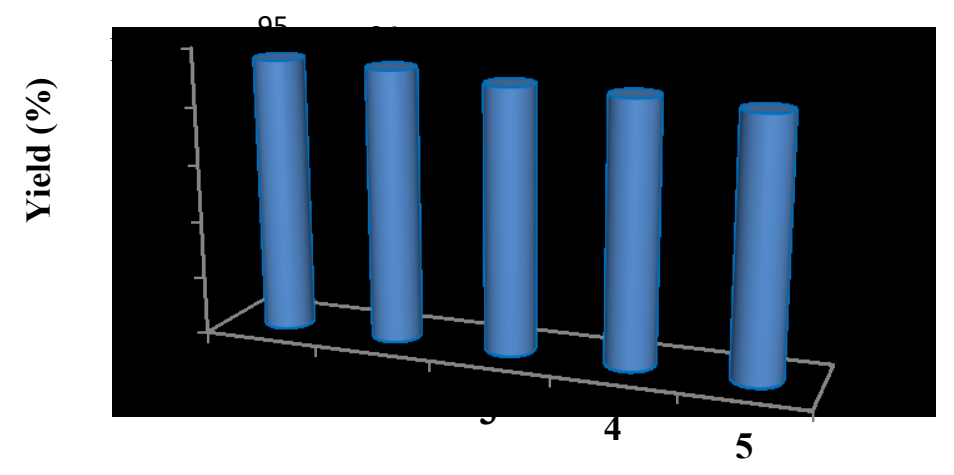

Reaction Cycle

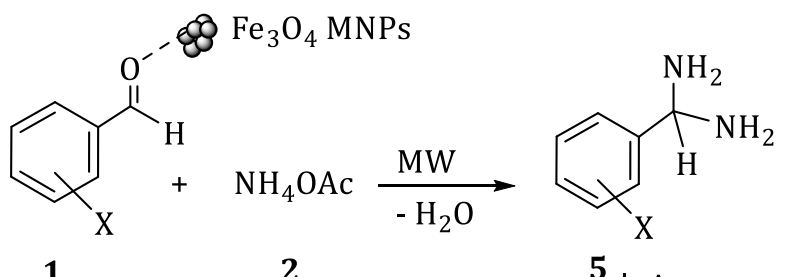

1

2
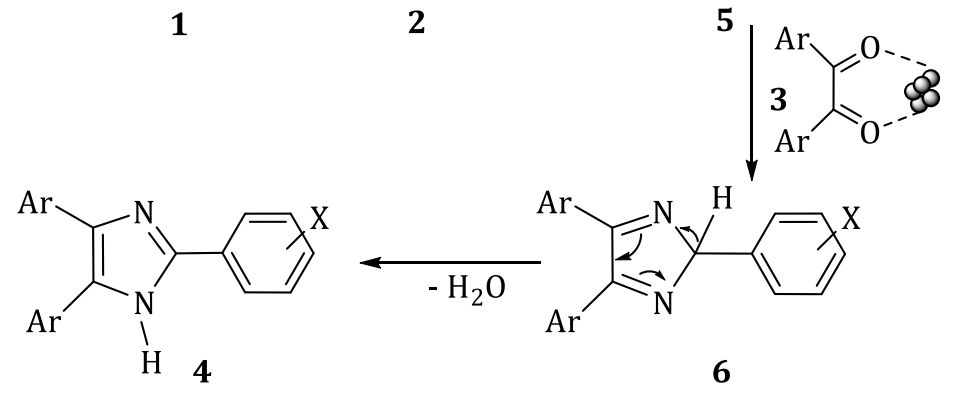

Scheme 2. Proposed mechanism for the synthesis of trisubstitutedimidazoles.

\section{Acknowledgements}

The authors are grateful for the financial support of the Payame Noor University (PNU) of Iran.

\section{Disclosure Statement}

No potential conflict of interest was reported by the authors.

\section{References}

[1]. Lombardino J.G., Wiseman E.H. J. Med. Chem., 1974, 17:1182

[2]. Lindberg P., Nordberg P., Alminger T., Brandstorm A., Wallmark B. J. Med. Chem., 1986, 29:1327

[3]. Pagano M.A., Andrzejewska M., Ruzzene M. J. Med. Chem., 2004, 47:6239 
[4]. Lee J.C., Laydon J.T., McDonnell P.C., Gallagher T.F., Kumar S., Green D., McNulty D., Blumenthal M.J., Keys J.R., Landvatter S.W., Strickler J.E., McLaughlin M.M., Siemens I.R., Fisher S.M., Livi G.P., White J.R., Adams J.L., Young P.R. Nature, 1994, 372:739

[5]. Heeres J., Backx L.J.J., Mostmans J.H., Vancustem J. J. Med. Chem., 1979, 22:1003

[6]. Wasserscheid P., Keim W. Angew. Chem. Int. Ed. Eng., 2000, 39:3772

[7]. Bourissou D., Guerret O., Gabbai F.P., Bertrand G. Chem. Rev., 2000, 100:39

[8]. Mukherjee A., Kumar S., Seth M., Bhaduri A.P. Ind. J. Chem. B, 1989, 28:391

[9]. Ayhan-Kilcigil G., Altanlar N. Turk. J. Chem., 2006, 30:223

[10]. Hadizadeh F.H., Hosseinzadeh V., Shariaty M., Kazemi S.J. Pharm. Res., 2008, 7:29

[11]. Shingalapur R.V., Hosamani K.M., Keri R.S. Eur. J. Med. Chem., 2009, 44:4244

[12]. Ozkay Y., Işıkdağ I., Incesu Z., Akalin G. Eur. J. Med. Chem., 2010, 45:3320

[13]. Tonelli M., Simone M., Tasso B., Novelli F., Biodo V. Bioorg. Med. Chem., 2010, 18:2937

[14]. Bhandari K., Srinivas N., Marrapu V.K., Verma A., Srivastava S.N., Gupta S. Bioorg. Med. Chem. Lett., 2010, 20:291

[15]. Srinivas N., Plane S., Gupta N.S., Bhandari K. Bioorg. Med. Chem. Lett., 2009, 19:324

[16]. Wolkenberg S.E., Wisnoski D.D., Leister W.H., Wang Y., Zhao Z., Lindsley C.W. Org. Lett., 2004, 6:1453

[17]. Shaabani A., Rahmati A. J. Mol. Catal. A, 2006, 249:246

[18]. Kidwai M., Mothsra P., Bansal V., Somvanshi R.K., Ethayathulla A.S., Dey S., Singh T.P. J. Mol. Catal. A, 2007, 265:177

[19]. Khosropour A.R. Ultrason. Sonochem., 2008, 15:659

[20]. Samai S., Nandi G.C., Singh P., Singh M.S. Tetrahedron, 2009, 65:10155

[21]. Teimouri A., Najafi Chermahini A.R. J. Mol. Catal. A, 2011, 346:39

[22]. Sivakumar K., Kathirvel A., Lalitha A. Tetrahedron Lett., 2010, 51:3018

[23]. Xia M., Lu Y.D. J. Mol. Catal. A, 2007, 265:205

[24]. Chary M.V., Keerthysri N.C., Vupallapati S.V.N.,Srinivasu V.N., Lingaiah N., Kantevari S. Catal. Commun., 2013, 2008:9

[25]. Zang H., Su Q., Mo Y., Cheng B.W., Jun S. Ultrason. Sonochem., 2010, 17:749

[26]. Murthy S.N., Madhav B., Nageswar Y.V.D. Tetrahedron Lett., 2010, 51:5252

[27]. Maleki, A., Alirezvani, J. Chil. Chem. Soc., 2016, 61, 3 N

[28]. H. Naeimi, D. Aghaseyedkarimi. New J. Chem., 2015, 39:9415

[29]. Rezayati S., Torabi Jafroudi M., Rezaee Nezhad E., Hajinasiri R., Abbaspour S. Research on Chemical Intermediates, 2016, 42:5887

[30]. Caddick S. Tetrahedron Lett., 1995, 51:10403 
[31]. Taghavi Fardood S., Ramazani A., Ayubi M., Moradnia F., Abdpour Sh., Forootan R. Chem. Methodol., 2019, 3:519

[32]. Kargar-Dolatabadi A., Zare A. Chem. Methodol., 2019, 3:655

[33]. Karami M., Gholami B., Hekmat-Zadeh T., Zare A. Chem. Methodol., 2019, 3:509

[34]. Sangshetti J.N., Kokare N.D., Kothakar S.A., Shinde D.B. Mont. Fur. Chem., 2008, 139:125

[35]. Abd El Aleem M., El-Remaily A.A. Tetrahedron, 2014, 70:2971

[36]. Mardani H.R., Ziari M. Res. Chem. Int., 2018, 44:6605

How to cite this manuscript: Hamid Reza Mardani*, Mehdi Forouzani, Rasoul Emami. Efficient and green synthesis of trisubstituted imidazoles by magnetically nanocatalyst and microwave assisted. Asian Journal of Green Chemistry, 3(4) 2019, 525-535. DOI: 10.33945/SAMI/AJGC/2019.4.9 